\title{
BASES NEUROBIOLÓGICAS DEL APEGO. REVISIÓN TEMÁTICA
}

\section{NEUROBIOLOGICAL BASIS OF ATTACHMENT. A THEMATIC REVIEW}

\author{
Gabriel Barg Beltrame \\ Universidad Católica del Uruguay, Uruguay
}

\begin{abstract}
Resumen: La teoría psicológica del apego, formulada originalmente por Bowlby en la década del 50, ha permitido profundizar el conocimiento del vínculo madre-bebé, identificar sus patologías y evaluar su influencia en las relaciones afectivas adultas. Actualmente, numerosos avances en el campo de las Neurociencias ofrecen la posibilidad de comprender la dimensión biológica del apego.

En este artículo, se revisan tres modelos que explican aspectos de la misma: el modelo evolutivo del sistema afectivo de Cuidado de Panksepp, mediado principalmente por la oxcitocina, el sistema de los reguladores ocultos de Hofer y Sullivan y la regulación epigenética del estrés de Meaney. Si bien estos modelos surgen de la investigación animal, tienen importantes implicancias para el estudio de la conducta humana, especialmente en la interacción entre genética, desarrollo y psicopatología.
\end{abstract}

Palabras clave: apego, neurobiología, desarrollo, reguladores, epigenética.

\begin{abstract}
There Psychological attachment theory, originally formulated by Bowlby in the 1950s, has allowed to deepen the knowledge of the link mother-baby, identify their pathologies and evaluate their influence on adult affective relations. Currently, numerous advances in the field of neuroscience offer the possibility of understanding the biological dimension of the attachment. In this article, three models that explain aspects of it are reviewed: the evolutionary model of the affective system of Care of Panksepp, mediated mainly by the oxytocin, the system of hidden regulators of Hofer and Sullivan and epigenetics of stress regulation of Meaney. While these models arise from animal research, they have important implications for the study of human behavior, especially in the interaction between genetics, development and psychopathology.
\end{abstract}

Keywords: attachment, neurobiology, development, regulators, epigenetics.

\section{INTRODUCCIÓN}

El concepto de apego ha sido extensamente estudiado en la Psicología. Desde su introducción formal por Bowlby a comienzos de la segunda década del siglo XX ha inspirado una nueva forma de entender el vínculo madre-hijo. Si bien algunos aspectos de este paradigma habían sido desarrollados en otros modelos como el psicoanálisis freudiano original y la etología, no fue sino hasta la conceptualización de Bowlby y sus seguidores que pudieron ser integrados en una estructura teórica original y específica, que se sustenta en bases biológicas (sistema conductual de control), sociales (impulso de contacto), cognitivas (registro y representación de las conductas y los vínculos) y dinámicas (significación de las conductas).

Desde esta perspectiva, el apego contribuye a la supervivencia física y psíquica del sujeto generando seguridad y facilitando el conocimiento del mundo, en la medida en que el niño va conformando modelos de representación internos que estructuran su vinculo con el mundo y con los otros significativos (Bowlby, 1979).

A partir de estas premisas teóricas, se desarrollaron instrumentos y técnicas para evaluar las formas del apego, y sus características saludables y patológicas. Se pueden citar como ejemplos de este importante desarrollo, la técnica de la Situación Extraña de Ainsworth (Ainsworth, 1969) y la AAI (Attachment Adult

Correspondencia: Gabriel Barg Beltrame. Universidad Católica del Uruguay.

Correo Electrónico: gbarg@ucu.edu.uy. 
Interview) de Main (Main, Hesse, \& Goldwyn, 2008). Estos instrumentos estandarizados, así como también otros de orden cualitativo, han permitido evaluar los distintos tipos de apegos y relacionarlos con patrones de conducta adulta y perfiles psicopatológicos. Si bien ha existido un considerable desarrollo de las medidas conductuales y psicométricas que permiten identificar los distintos estilos de apego y relacionarlas con sus consecuencias en el comportamiento adulto, existe consenso en la bibliografía por el cual definiciones conceptuales básicas permanecen en la formulación de Bowlby (Crowell \& Treboux, 1995; Levy, Ellison, Scott, \& Bernecker, 2011; Madigan et al., 2006).

La Neurología tradicionalmente se ha interesado por el estudio de la relación entre el funcionamiento del sistema nervioso y los procesos emocionales. A finales del siglo XIX, Broca ya había definido al lóbulo límbico y en 1937 Papez estableció una hipótesis de funcionamiento del mismo como base de los procesos emocionales. Yakovlev (1948) también discriminó las estructuras cerebrales específicamente relacionadas con la emoción (Heimer \& Van Hoesen, 2008; Kandel, Schawrtz, \& Jessell, 2000; Mega, Cummings, Salloway, \& Malloy, 1997). Mac Lean (MacLean, 1955) generó una teoría del sistema límbico, como cerebro visceral, cuya función consiste en sustentar funcionalmente la respuesta emocional. Más recientemente, este campo de estudio ha asumido el nombre de Neurociencia Afectiva, cuyo objeto es utilizar los avances tecnológicos a nivel de identificación de neurotransmisores, receptores y zonas de actividad cerebral para posibilitar la integración de los conocimientos desarrollados a nivel de la Psicología y la Psiquiatría con los provenientes de la Neurofisiología del comportamiento (Panksepp, 1998).

En esta línea, en los últimos años han surgido una serie de estudios que pretenden indagar específicamente en la neurobiología del apego. Estos estudios utilizan el concepto de apego de una forma operativa: un término descriptivo para los procesos que mantienen y regulan las relaciones sociales (incluyendo orientación, cuidado temprano, primeros aprendizajes, termorregulación y desarrollo sensoriomotor) (Hofer, 2006). Otro elemento a considerar es que si bien se cuenta con los primeros resultados en este campo, los principales grupos de investigación en la materia coinciden en que son avances incipientes. Young, Liu \& Wang (2008) dicen que estos estudios son "escasos" (p.401), para Moriceau \& Sullivan (2005) "solo han recibido atención reciente" (p.230), para Hofer (2006) "el término apego era rara vez utilizado por los psicobiólogos del desarrollo antes de la última década" (p.84) e incluso Zhang \& Meaney (2010) hablan de "nuevas pruebas"(p.439) al referirse a los procesos epigenéticos que se dan en la interacción madre-cría temprana.

Dado que muchas de las metodologías empleadas en esta línea revisten un carácter invasivo, existe gran cantidad de investigación psicobiológica realizada en animales. Si bien una simple extrapolación de datos de un campo a otro no es pertinente, existen fuertes fundamentos evolutivos para afirmar que los datos provenientes de la investigación animal aportan indicios interesantes para comprender el comportamiento humano. El propio Darwin estableció este patrón de comparación en su obra, tanto en el campo de la fisiología como en el de la expresión emocional (Darwin, 1872/1946). Por otra parte, toda una línea de investigación en biología, que comienza con la formulación de la Ley Biogenética de Von Baer, ha buscado sistematizar y cuantificar la recapitulación filogenética en la ontogenia (Alberch, Gould, Oster, \& Wake, 1979). Aplicando estos principios al estudio del sistema nervioso humano, se pueden resumir sus implicancias en los siguientes argumentos.

En primer lugar, el ser humano comparte con el resto de la escala zoológica casi la totalidad del código genético. En segundo lugar, el sistema nervioso humano anatómica y funcionalmente es una recapitulación filogenética de la evolución. De forma tal que los seres humanos comparten estructuras anatómicas con reptiles, aves, mamíferos y primates. A la cual se agrega un desarrollo mayor de la corteza cerebral de asociación (neocortex). Sin embargo, la totalidad de las estructuras corticales y sub-corticales son compartidas por estas distintas especies. $Y$ finalmente, la respuesta emocional presenta algunos componentes estructurales comunes entre los animales y los humanos, especialmente en la respuesta a la amenaza (Ledoux, 2000; J. Panksepp, Moskal, J. B. Panksepp, \& Kroes, 2002; J. Panksepp \& J. B. Panksepp, 2000).

Esto es especialmente válido para el concepto de apego. El concepto mismo surge a partir del estudio de la conducta maternal de aves y primates en el marco de la etología. En este sentido, Bowlby subrayó la importancia de no 
perder de vista la función biológica adaptativa de las conductas de apego así como la importancia de los factores genéticos que influyen en las conductas de la especie y del individuo (Bowlby, 1979).

\section{OBJETIVOS}

Partiendo de este marco, el objetivo del trabajo será revisar los hallazgos neurocientíficos en la materia, vinculándolos con el nivel comportamental de los conocimientos psicológicos en el tema.

Identificar los principales modelos neurobiológicos que explican conductas aisladas o integradas del sistema de apego.

Comparar dichos modelos e identificar posibles problemas de investigaciones futuras.

\section{MÉTODO}

Para seleccionar la bibliografía se tomaron los siguientes criterios de búsqueda:

- Trabajos publicados entre 2001 y 2011

- Estudios realizados en animales y en humanos

- Palabras-frases clave: (Apego), (Bases neurobiológicas del apego), (Bases neurobiológicas de las emociones) y (Psicobiología del desarrollo)

- Medios de búsqueda: Bases de datos electrónicas (Ebsco, PsychINFO, APAPsycNET, Ovid, Science Direct, Interscience, Springer, MedLINE, PubMed, Scielo)

- Se priorizaron los trabajos empíricos pero también se incluyeron aquellas revisiones de grupos de investigación en las cuales se sistematizan los hallazgos de sus experimentos en los últimos años. Tal es el caso de la revisiones de Hofer (Hofer, 2006), Hofer \& Sullivan (Hofer \& Sullivan, 2001), Moriceau \& Sullivan ( Moriceau \& Sullivan, 2005), Young, Liu \& Wang (Young, Liu, \& Wang, 2008) y Zhang \& Meaney (Zhang \& Meaney, 2010).

- Se incluyen trabajos previos al período de revisión definido solo cuando revisten carácter histórico, definen por primera vez un concepto utilizado o son los primeros en presentar un hallazgo empírico.

- Se consideraron solo aquellos trabajos que utilizan explícitamente el concepto de apego, teórica u operativamente.

\section{RESULTADOS}

\section{La teoría del Apego}

Para Bowlby (1958) el apego se formaría a partir de la necesidad del infante humano de mantener proximidad con ciertas figuras que le provean de lo necesario para su supervivencia. Esta necesidad daría lugar a un sistema conductual de control, que se apoya en cinco respuestas instintivas humanas: chupar, llorar, aferrarse, aproximarse y sonreír. Estas respuestas son independientes pero serían integradas a través de sucesivas experiencias con los cuidadores, que al ser internalizadas, irían conformando la conducta global de apego.

Cuando este sistema se encuentra en pleno funcionamiento el niño puede controlar el acceso a las figuras de apego y mantener un grado de proximidad razonable, incluso en situaciones que no conllevan una amenaza grave.

Es importante diferenciar entre la conducta de apego y el vínculo de apego. El vínculo de apego es el lazo afectivo por las personas que tienen una significación especial en su vida. Decir que un niño o una persona tiene apego a alguien significa que está absolutamente dispuesto a buscar la proximidad y el contacto con ese individuo, sobre todo ante la sensación de inseguridad. Por otra parte, la conducta de apego se refiere a cualquiera de las diversas formas de conducta que tiene como resultado el logro o la conservación de la proximidad con otro individuo claramente identificado al que se considera mejor capacitado para enfrentarse al mundo.

Esta conceptualización se apoyaría fundamentalmente en los avances de la Etología, ciencia que estudia el comportamiento animal comparado. La teoría de la impronta establece una base de comparación natural en relación a las conductas humanas de apego. La impronta filial o troquelado es una forma de aprendizaje en que los animales precociales en sus primeros días aprenden a aproximarse y seguir al primer objeto relativamente grande que ven en movimiento (Bateson, 1990; Lorenz, 1973).

Estudiando el modo en que se desarrolla la conducta de apego en el bebé humano, y cómo se centra en una figura discriminada, en relación a cómo se desarrolla en otros mamíferos y aves (precociales), Bowlby concluye que puede incluirse dentro de las pautas generales de 
impronta (siempre que este término se aplique en un sentido genérico amplio). El elemento que tienen en común todos estos tipos de conductas es que buscan el objetivo de obtener la proximidad deseada (Bowlby, 1969). Este tipo de conductas comenzaría aproximadamente a los 4 meses de edad, a partir de los cuales el bebé empieza a sonreír y vocalizar frente a la madre así como también empieza a seguirla con la mirada. La función biológica-evolutiva de la conducta de apego sería la protección frente a los animales de presa. De esta forma, el poder lograr la conducta de proximidad con la madre sería una de las claves de la supervivencia de la cría en las especies superiores. El rol activo en este acercamiento lo tiene en un primer momento la madre. El bebé lo provoca a través de "señales" tales como el llanto, la sonrisa, el balbuceo, los gestos y el llamado cuyo objetivo es llevar a la madre hacia el hijo. Posteriormente, el niño asume este rol desarrollando las "conductas de acercamiento" cuyo objetivo es llevarlo a él hacia la madre.

En la construcción del sistema de apego en el vínculo madre-hijo, se pueden identificar una serie de fases (Bowlby, 1969; Ainsworth, 1969):

1- Fase de pre apego: (primeros dos meses). Orientación y señales sin discriminación de figura. Serían aquellos comportamientos de las primeras semanas de vida del bebé, que forman parte de su bagaje genético y que se activan frente a la presencia humana. Se caracteriza por la aparición de un amplio repertorio de señales en el bebé que son, en su mayoría, de carácter reflejo, aunque también posee otras capacidades sensoriales y perceptivas que le permiten comunicarse y conocer a las personas que le rodean. Ejemplos de estas conductas serían orientar la mirada hacia una persona, sonreírle, dejar de llorar, tratar de aferrar.

2- Fase de formación del apego (2 a 6 meses) Durante estos meses, el bebé empieza a dar muestras de poder diferenciar a las personas familiares de las desconocidas, por lo que tiene una mayor tendencia a iniciar interacciones sociales con el cuidador o cuidadores principales. Por lo tanto, los comportamientos reseñados en la fase anterior se orientan ahora hacia el cuidador.

3- Fase clara de apego (seis meses a tres años) En esta nueva etapa se producen una gran cantidad de cambios que dan lugar a la consolidación de la vinculación afectiva. No sólo el sistema de apego (como conjunto de conductas que se encuentra organizado en torno a una meta, a saber la proximidad y el contacto físico con la figura de apego) se consolida en esta fase. Otros tres sistemas conductuales relacionados con él también hacen su aparición en ella. El sistema de miedo contiene el conjunto de conductas de cautela, temor e inhibición que aparecen cuando el niño se enfrenta a una estimulación novedosa, sobre todo si proviene de personas no familiares. El sistema afiliativo recoge el repertorio de conductas encaminadas a la búsqueda de la proximidad e interacción con personas conocidas. El sistema exploratorio, favorecido por las nuevas posibilidades de desplazamiento autónomo, contribuye a que el niño pueda mostrar conductas encaminadas a conocer y explorar el entorno físico. Se buscará en consecuencia el mantenimiento de la proximidad con una figura discriminada por medio de la locomoción y de las señales. Cuando el niño logra moverse por si mismo, agrega este nuevo repertorio conductual a sus recursos para obtener la proximidad de la madre. Esta situación novedosa introduce el equilibrio entre las conductas del niño orientadas hacia la exploración y hacia la seguridad. Ambas son imprescindibles para su desarrollo. En un proceso normal, en función de la sucesión de conductas de exploración-acercamiento el niño empieza a construir el concepto de "base segura": la madre como elemento independiente, permanente en tiempo y espacio, al que puede recurrir más allá de no estar en contacto presente.

4- Formación de una relación recíproca (tres años en adelante; este tipo de interacción madre-hijo dura toda la vida en los seres humanos). Ainsworth plantea un interesante vínculo entre las fases del apego de Bowlby y las etapas cognitivas de Piaget. Para lograr una relación recíproca el niño debe haber podido superar el egocentrismo (Piaget, 1964/1991). Debe ser capaz de interpretar los objetivos de la madre para poder interactuar con sus propios objetivos.

Ambos autores (Bowlby y Ainsworth) resaltan que las conductas de apego no son priva- 
tivas de la infancia sino que se desarrollan a lo largo de toda la vida y se ven potenciadas en las situaciones de inseguridad. Incluso hay figuras de apego que pueden permanecer más allá de la infancia, como los padres. Lo que cambia son las estrategias que se usan para establecer el apego. Esto es visto como parte del desarrollo saludable de la persona.

Para que la interacción recíproca se produzca exitosamente deben darse una serie de respuestas por parte de la madre. Por un lado, es fundamental la sensibilidad de la misma ante las señales del bebé y la sincronización de sus intervenciones en relación a éstas. Por otro, el hecho de que las iniciativas de contacto del bebé lleven a respuestas de la madre previsibles y coherentes con sus necesidades.

Esto permite el desarrollo de los dos aspectos de un vínculo de apego saludable:

a- que los padres le proporcionen al niño una base segura

b- que lo animen a explorar a partir de ellos (Bowlby, 1979).

Las características de la construcción del vínculo de apego definen modelos representativos de si mismo y de los otros que permanecen actuando en otras etapas de la vida y condicionan futuros vínculos.

M. Ainsworth, una de las colegas de Bowlby, desarrolló en los años 60 , una serie de estudios que le permitieron establecer una clasificación empírica de las diferentes modalidades de apego. Comenzó con un estudio longitudinal de 26 pares de madres y bebes en sus ambientes naturales. Este estudio realizado en Baltimore, Maryland consistió en tres visitas semanales, de cuatro horas de duración durante el primer año de vida en las cuales los investigadores registraban el comportamiento de los bebés y la sensibilidad en las respuestas de las madres al mismo. Posteriormente, diseñó un modelo denominado "Situación Extraña" (Strange Situation), un procedimiento de laboratorio semiestructurado en el que podía observar a los bebés respondiendo frente a distintos estímulos (encontrarse en un lugar nuevo, una mujer adulta extraña, estar separado de la madre por un período breve y estar solo en un lugar no conocido por un momento). Este estudio incluyó 106 bebés, 23 de los cuales pertenecían al estudio longitudinal. En la Situación Extraña, jueces experimentados codificaron el comportamiento interactivo en cuatro escalas: proximidad y bús- queda de contacto, mantenimiento del contacto, resistencia y evitación. Como resultado de estas investigaciones, Ainsworth definió tres patrones de apego: el Apego Seguro, el Apego Ansioso/ Evitativo y el Apego Ansioso/Ambivalente (Ainsworth, 1969).

En el Apego Seguro, los niños usaban a la figura de apego como una base segura a partir de la cual explorar el ambiente. Cuando se enfrentaban a eventos estresantes (como la separación en un ambiente desconocido), se acercaban o realizaban algún tipo de señal que les permitiera aumentar el grado de proximidad con la figura de apego. Cuando este era obtenido volvía a continuar con su exploración. En el Apego Ansioso/Evitativo, los niños que enfrentaban un momento de separación con sus madres eran relativamente indiferentes cuando aquellas retornaban: no las saludaban, ignoraban sus intentos de tomar contacto y actuaban sin darle mayor importancia a su presencia. En el caso del Apego Ansioso/Ambivalente, se observaron comportamientos combinados de ansiedad y acercamiento. Cuando estos niños se juntaban con sus madres luego de una breve separación emitían señales de ansiedad paralelamente a su comportamiento de apego.

Dantagnan (Dantagnan, 2005), quien describe las modalidades de apego en niños víctimas de violencia y maltrato, define al estilo de Apego Evitativo como aquel que se produce cuando las respuestas obtenidas por parte de la madre no solo no satisfacen las necesidades afectivas del niño, sino también son generadoras de estrés. En ese caso, la estrategia adoptada por el niño es la inhibición de las conductas de apego y de su mundo emocional para evitar el dolor del rechazo, tal como sostiene Bowlby. En este caso la estrategia para obtener la seguridad consiste en incrementar las conductas de apego como un modo de asegurarse la proximidad de la figura de apego.

Al relevar poblaciones infantiles sometidas a condiciones de alto riesgo (víctimas de maltrato, madres psiquiátricas, etc), Main y Solomon introdujeron en 1986 un cuarto tipo de codificación del apego: el estilo Desorganizado/Desorientado. Estos niños parecen no poseer una estrategia consistente para manejar el alejamiento y la proximidad. Muestran signos de depresión clínica y combinaciones de comportamiento evitativo, hostil y de apego (Main, Hesse \& Goldwin, 2008). Se trata de niños cuyas experiencias tempranas son 
tan dolorosas que sus estrategias defensivas colapsan, volviéndose caóticas. Se enfrentan permanentemente a la paradoja insoluble de que su figura de apego, que debería ser su máxima fuente de protección, es, en realidad, una de sus principales causas de amenaza y daño. Según Dantagnan (2005), alrededor de un 75 a $80 \%$ de la población de niños maltratados presenta estilo de apego desorganizado.

Main también introdujo un procedimiento de investigación del apego en adultos, la Adult Attachment Interview (AAI) (Main, Hesse \& Goldwin, 2008). Se trata de una entrevista semi-estructurada desarrollada para evaluar las formaciones adultas equivalentes a las estrategias de apego infantiles. La entrevista dura aproximadamente una hora y busca obtener información acerca de cómo la persona procesa sus relaciones con los padres y otras figuras de apego a partir de sus experiencias en la temprana infancia. La entrevista no se codifica en función de la evaluación positiva o negativa que realiza la persona de dichas experiencias, sino en términos del análisis narrativo de las mismas. Esto es, como el individuo organiza su atención y su discurso relativo a las situaciones de apego (Agrawal et al, 2004). Un discurso flexible y coherente sobre las experiencias positivas y negativas de apego se codifica como Autónomo (el equivalente a Seguro en la infancia), estrategias para evitar la referencia a las mismas se codifican como Rechazante (Evitativo en la infancia) y estrategias de discurso hiperactivadas en la referencia al apego se codifican como Preocupado (Ambivalente en niños).

Posteriormente, los autores agregaron la categoría No resuelto (Unresolved) que apareció en el discurso de adultos que se referían a experiencias de pérdida y trauma. Este discurso se caracterizaba por no mostrar una estrategia de abordaje consistente de estas situaciones, que evidentemente no habían sido elaboradas por la persona. Esta categoría correspondería al patrón Desorganizado en niños y se le asigna una segunda clasificación que hace referencia a la mejor estrategia que trata de poner en práctica, aunque sea fallida. Por ejemplo, No resuelto/ Preocupado o No resuelto/Rechazante. Este último estilo de apego, tanto en adultos como en niños estaría asociado a un nivel de psicopatología mayor en la infancia y adolescencia (Lyons-Ruth et al, 2005).

Como visión global del apego, Lyons-Ruth y otros (Lyons-Ruth et al., 2004) basándose en la perspectiva de Bowlby, comparan el sistema del apego con las funciones que cumple el sistema inmunológico. Mientras que este último sería el sistema biológico encargado de combatir la amenaza de enfermedad física, la función del sistema de apego sería combatir la activación ansiosa, el miedo o el stress provocado por amenazas ambientales. Sin embargo, así como el sistema inmunológico puede dejar de funcionar correctamente y provocar enfermedades autoinmunes, si no se dan las condiciones adecuadas de interacción madre- hijo el sistema del apego puede dejar de brindar su función protectora y convertirse en si mismo en fuente de trastornos de diverso tipo.

\section{Bases neurobiológicas del apego}

Como se mencionó anteriormente, el concepto de apego hunde sus raíces conceptuales en el imprinting; el proceso por el cual las crías de determinadas especies fijan la imagen de determinada figura adulta (generalmente su madre, pero no necesariamente) y la toman como objeto referencial al que siguen a todas partes. Este proceso se da en las especies precociales, especialmente aves. En estas especies las crías nacen con sus sistemas perceptivos y motores prontos y, por lo tanto, pueden moverse y seguir a su objeto maternal rápidamente. De hecho se las llama también "nidífugas" porque a las pocas horas de nacer salen del nido para seguir a su figura de referencia.

Por el contrario, el ser humano, al igual que el perro o el conejo, se encuentra entre las especies altriciales. Las crías de estas especies nacen con los mecanismos perceptivos escasamente desarrollados y con poca movilidad. Para adquirir las características del adulto deben pasar por un largo proceso de aprendizaje. Dentro de las especies altriciales, el período de crecimiento del ser humano es especialmente lento y requiere un largo aprendizaje. Para que el mismo sea posible es necesario que se desarrolle el proceso de apego, es decir, un tipo determinado de relación maternal que permita que el hijo sobreviva biológica y psicológicamente.

\section{a) El apego como sistema de Cuidado}

Según Paanksepp (1998), el comportamiento maternal tiene un fuerte componente biológico, especialmente el que ocurre inmedia- 
tamente antes y después del parto. Si bien las interacciones socio-emocionales y cognitivas específicamente humanas aportan a configurar el comportamiento maternal, sin la alteración de determinados componentes neuroquímicos, hormonales y de neurotransmisión, dichas experiencias carecerían de la intensidad emocional que las caracteriza. Esta situación tendría su lógica desde el punto de vista evolutivo ya que las conductas maternales de sostén, vitales para la supervivencia, no quedarían libradas al aprendizaje individual sino que se transmitirían a nivel de la especie por medio de mecanismos biológicos hereditarios.

Los estudios pioneros de Spitz (Spitz, 1945) habían demostrado en los años 40 que el contacto y cuidado humano era tan necesario para sobrevivir para los bebes como el alimento o el abrigo. Por otra parte, Harlow con sus experimentos con primates (monos macacos) demostró que los bebés prefieren un muñeco que simula su madre cuando está forrado con materiales cálidos (lana, tela, guata) que cuando solamente es una estructura de alambre. Aún cuando esta preferencia les implique la pérdida de alimento. Además, cuando estaban en presencia de la madre "cálida" desarrollaban un comportamiento motor de exploración mucho más intenso (Harlow, 1958).

El desarrollo de esta línea de investigación ha llevado a la búsqueda de los sistemas que conforman el apego, estudiando los cambios psicobiológicos que componen la escala dimensional que va desde la atracción y el encuentro hasta la soledad y el aislamiento. Estos estudios parten de la base de que se trata de un sistema neurobiológico único que propicia por un lado el acercamiento y el apego y por otro activa respuestas desagradables que tienden a inhibir la separación. O funcionan como señales para que el individuo busque a su figura de apego, o para que la misma se dirija hacia él. Los input activadores del sistema provendrían de distintos sistemas sensoriales, predominando en el sistema de acercamiento los somatosensoriales, olfatorios y auditivos y en el sistema de separación los visuales, vestibulares (posición/equilibrio) y los sensores hipotalámicos de hambre y temperatura. EI sistema de apego habría evolucionado filogenéticamente de procesos más arcaicos como la fijación al lugar de nacimiento de los reptiles, el mecanismo del dolor y la termorregulación (Panksepp, 1998).
Para este autor, las sustancias que controlan estos mecanismos son algunos neuropéptidos como la oxcitocina y la prolactina así como también los opiodes endógenos tales como las endorfinas. Se ha demostrado, principalmente en la investigación animal, que tanto los opioides cerebrales como los circuitos sobre los que actúa la oxitocina son activados por actividades sociales tales como el juego, el acicalamiento de las crías y la actividad sexual. Por otra parte, su administración en el sistema nervioso central actúa disminuyendo las respuestas negativas de aislamiento. De esta forma, se postula que los cambios en la acción de estos neuropéptidos sobre el cerebro pueden estar relacionados con el sentimiento de base segura del niño así como con el comportamiento maternal en adultos.

La oxcitocina es una hormona liberada en el sistema nervioso central por la neurohipófisis. Ha sido tradicionalmente estudiada en relación a su papel promotor de las contracciones del útero en el parto y con el amamantamiento. Desde esta nueva perspectiva se la ha estudiado también por su papel iniciador de comportamientos maternales de cuidado (su mantenimiento en el tiempo obedecería a otros factores) en numerosas especies. Esta función de la oxcitocina ha sido evaluada recientemente en parejas humanas. En un estudio longitudinal de seis meses de seguimiento con 160 madres y padres que vivían con sus bebés recién nacidos, Gordon, Zagoory, Leckman \& Feldman (Gordon, Zagoory-Sharon, Leckman, \& Feldman, 2010) mostraron que los niveles de oxcitocina aumentaron durante el período. Además, filmaron y caracterizaron las conductas de cuidado de los progenitores encontrando una correlación entre el aumento de oxcitocina y los comportamientos de contacto, vocalizaciones afectuosas, estimulación táctil y presentación de objetos.

Con la prolactina sucede algo similar. Por otro lado, los opioides internos son neuropéptidos cuya función originaria es calmar el dolor pero cuya presencia también provoca sensaciones placenteras. Los opioides exógenos al organismo, como la heroína, simulan la farmacodinamia de estas sustancias. De hecho, Panksepp (1998) compara el funcionamiento químico del vínculo social con la adicción a las drogas. En ambos casos se produce un comportamiento que produce placer. $Y$ en ambos casos hay síntomas que tienen que ver con la privación de ese comportamiento, en un caso 
por la separación de la figura de apego y en otro por la abstinencia en el consumo. Por supuesto, uno de los comportamientos es un proceso natural y humanizador y el otro es una adicción incapacitante a un fármaco. Esta función de los opiodes endógenos ha sido corroborada en monos (Rhesus), los cuales aumentaban el nivel de su interacción social (aseo por pares) cuando recibían un bloqueador de los mismos (naltrexona) (Graves, Wallen, \& Maestripieri, 2002). Por otra parte, se puede observar que el desbalance de estos sistemas químicos genera consecuencias psicopatológicas graves. Por ejemplo, la depresión post-parto y la psicosis puerperal han sido relacionadas con altos niveles de $\beta$-casomorfina, un opioide derivado de la leche (Nyberg, Linstrom y Terenius, 1988) que funcionaría como bloqueador de la producción de opioides endógenos.

Los circuitos neurales que funcionan en base a estas sustancias estarían integrados por estructuras que Paanksepp (1998) denomina Sistema de Cuidado. Entre otras se puede citar como integrantes del mismo a la corteza cingulada, el área septal, los núcleos basales de la estría terminal, la amígdala y algunas áreas del hipotálamo. Por otra parte, existiría un sistema con particularidades neuroquímicas propias destinado a mediar las respuestas de separación. La respuesta de este tipo que más ha sido estudiada en diversas especies son las vocalizaciones que realiza la cría cuando es separada de su madre, o el llanto en el ser humano. Pero también hay otras como la pérdida de apetito, de sueño, la irritabilidad o la depresión. Este sistema se denomina de Pánico y su principal neuromodulador sería el glutamato. Más allá de que otros neuromoduladores como la noradrenalina, la serotonina y el factor de liberación de la corticotropina (CRF) también regulan el nivel de las vocalizaciones originadas por la separación cuando aumenta su nivel en el sistema nervioso central ( Panksepp, 2006;Young, Liu, \& Wang, 2008).

Estos mismos neuropéptidos estarían influyendo en los circuitos que median el comportamiento sexual y el reconocimiento social. De manera que existiría un componente común tanto en el amor maternal, como en el sexual y en el comportamiento social en general. Se ha demostrado que ratones que habían sido genéticamente impedidos de producir oxcitocina (knock out) en los bulbos olfatorios, la amígdala y el septum fallaban al reconocer pares fami- liares y no-familiares. Por otro lado, cuando se les administraba oxcitocina previo al primer encuentro mejoraban significativamente en esta tarea, mostrando una activación importante en la amígdala media (Ferguson, Aldag, Insel, \& Young, 2001; Ferguson, Young, \& Insel, 2002). Por otra parte, Zak, Kurzban y Matzner (Zak, Kurzban, \& Matzner, 2005) demostraron en humanos que el nivel de oxcitocina aumenta cuando una persona cree que otra confía en ella.

\section{b) El apego como sistema de regulación}

Para Hofer y Sullivan (2001), las respuestas de separación no son únicamente la contracara del funcionamiento psicobiológico en las situaciones de apego. De hecho no forman tampoco una unidad sino que cada una de ellas tendría un funcionamiento autónomo. La madre ajustaría el funcionamiento de cada uno de estos aspectos a través de "reguladores ocultos" (hidden regulators). Son denominados de esa manera porque no son identificados como tales a través de la simple observación. Por ejemplo, en ratas se ha estudiado cómo la suspensión experimental del aseo cotidiano de las madres a sus crías disminuye rápida y considerablemente el nivel de hormona del crecimiento de las mismas. Sucede que cuando la madre rata lame a su cría además de higienizarla e inmunizarla, está modulando la sensibilidad de determinados receptores a la serotonina, cuyo funcionamiento a su vez, regula la liberación de la hormona del crecimiento por la hipófisis. Otra de estas funciones sería la regulación de la presión sanguínea de la cría a través del amamantamiento (Shair, Brake, Hofer, \& Myers, 1986).

Al parecer, numerosos procesos biológicos del bebé estarían regulados a través de "reguladores ocultos" que la madre ajustaría a través de la relación de apego (ver ejemplos en Tabla). Muchos podrían aplicarse en humanos. Además, estudiar el comportamiento de apego en base a sus aportes a la regulación fisiológica puede contribuir a explicar la situación paradójica que se da frente a una conducta maternal/ paternal abusiva. Bolwby (Bolwby, 1969) sostuvo que frente a una conducta abusiva de la figura de cuidado, inicialmente las conductas de apego se incrementan para luego establecerse en un patrón de alejamiento (que puede derivar en distintos estilos de apego). La hipótesis de la función reguladora del apego puede explicar 
esta respuesta, no solo en función de la ruptura de un vínculo emocional global sino de la desestabilización de aspectos concretos del organismo por la pérdida masiva de reguladores (Hofer, 2006).

Siguiendo esta línea, Moriceau y Sullivan (Moriceau \& Sullivan, 2005) desarrollaron un modelo experimental del apego en ratas. Este modelo se basa explícitamente en dos premisas sobre el apego de Bolwby. La primera, es el desarrollo rápido de la conducta de apego hacia el cuidador y la segunda es la resistencia a extinguir estas conductas aún cuando exista un tratamiento abusivo por parte del mismo. Para eso estudiaron la potenciación del condicionamiento del olor materno por parte de la cría y la resistencia a asociar este olor con un suceso aversivo.

Al hacerlo señalan que existe una serie de condiciones anatómicas y funcionales en el sistema nervioso central que sostienen estos procesos y que cambian a partir del décimo día de vida. Esto permite que se produzcan significativos procesos de condicionamiento aún cuando las estructuras protagonistas del aprendizaje en adultos aún no estén totalmente desarrolladas (amígdala, hipocampo y corteza frontal).
De manera que este aprendizaje inicial se realizaría a partir de estructuras específicamente orientadas al mismo. En concreto, sería posible porque este aprendizaje produciría una activación del bulbo olfatorio y su consiguiente modificación estructural. Esto sería posible por el desarrollo postnatal de las proyecciones noradrenérgicas provenientes del locus coeruleus (McLean \& Shipley, 1991). Por otra parte, el déficit en el condicionamiento aversivo del olor materno puede relacionarse con la inmadurez de la amígdala así como del limitado funcionamiento del eje hipotálamo-hipófiso-adrenal (Moriceau, Raineki, J. D. Holman, J. G. Holman, \& Sullivan, 2009; Moriceau, Shionoya, Jakubs, \& Sullivan, 2009). Los autores del modelo sostienen que existe una adecuación del desarrollo del sistema nervioso para adaptarse a los distintos ambientes en los que se encuentra la cría. En un comienzo cuando se encuentra en el nido y no tiene capacidad de movimiento autónomo su supervivencia depende de la proximidad con la madre y esta no puede disolverse aunque la misma desarrolle conductas agresivas (situaciones como mordidas o que la madre camine encima de las crías son frecuentes en el nido).

Tabla

Ejemplos de reguladores ocultos en crías de ratas. Tomado de Hofer y Sullivan (2001)

$\begin{array}{lll}\text { Sistema } & \text { Regulador }\end{array}$

$\begin{array}{lll}\text { Comportamental } & \text { Nivel de actividad } & >\text { Calor } \\ \text { Succión } & >\text { Distensión gástrica } \\ \text { Lutonómico } & \text { Leche en los receptores } & >\text { Frecuencia cardíaca } \\ \text { Endóstricos } & \text { Estimulación táctil } & <\text { HCTH, RCH } \\ \text { Ritmos circadianos } & \text { Ritmos de lamido y } & >\text { Duración sueño REM } \\ & \text { alimentación } & \text { Duración/frecuencia }\end{array}$

Nota: $>=$ Aumento $;<=$ Disminución. Adaptado de Hofer \& Sullivan (2001). 
Estas afirmaciones adquieren una significación mayor a la luz de los estudios del impacto de las conductas de apego en la regulación de la expresión genética (Champagne et al., 2008; Liu et al., 1997). Esta línea de investigación ha demostrado como el comportamiento maternal de cuidado en ratas modifica la expresión de los genes encargados de expresar los receptores glucocorticoides en el hipocampo. La mayor o menor disponibilidad de estos receptores en esta zona y otras corticolímbicas condiciona el funcionamiento del eje Hipotálamo-HipófisoAdrenal (HHA). Este sistema es clave en la activación de las respuestas comportamentales, emocionales, autonómicas y endócrinas a los estresores ambientales (Bale et al., 2002; Bale $\&$ Vale, 2004). Frente a un estímulo amenazador o estresor el hipocampo actúa sobre el hipotálamo generando la descarga del factor de liberación de la corticotropina (CRF) sobre la hipófisis anterior, que a su vez, sintetiza y libera adrenocorticotropina (ACTH) sobre la corteza suprarrenal. Esta libera distintos glucocorticoides, como el cortisol, que cumple una importante función en el mantenimiento de la respuesta al estrés, por ejemplo, favoreciendo el incremento del nivel de azúcar en la sangre y la metabolización de grasas, proteínas e hidratos de carbono. El nivel de glucocorticoides en sangre es captado por receptores en el cerebro, fundamentalmente en el hipocampo y otras zonas del prosencéfalo. Cuando el nivel de los mismos llega a determinado umbral, el hipocampo inhibe la liberación de CRF, por lo cual a través de un mecanismo de retroalimentación negativa disminuye la respuesta al estrés (Weaver, Meaney, \& Szyf, 2006). De manera que si existe mayor cantidad de receptores en el hipocampo, la retroalimentación negativa se verá incrementada.

La interacción madre-cría a través del lamido tiene un efecto regulatorio en la expresión genética de estos receptores. Sorprendentemente, cuanto más frecuente sea la conducta maternal de lamido en la primera semana de vida de la cría mayor será la expresión genética de estos receptores $y$, por lo tanto, menor la respuesta frente a eventos estresantes. Esta regulación es epigenética, es decir, se da a través de modificaciones funcionales del genoma que no involucran cambios en la secuencia de nucleótidos (Zhang \& Meaney, 2010). De acuerdo a los estudios de Meaney y su grupo, la transcripción del gen que regula la expresión de los receptores glucocorticoides del hipocampo es alterada por el nivel de serotonina (5-HT). El mismo desencadena la activación de varias proteínas y factores transcripcionales potenciando la acción del promotor en la expresión de dicho gen. Un aumento en los niveles de 5-HT en crías de ratas, producto de un lamido más frecuente en la primera semana de vida, regula en más la expresión genética de los receptores de glucocorticoides.

McGowan et al (Mcgowan et al., 2009), aplicaron esta hipótesis al estudio de seres humanos. Examinaron post-mortem neuronas del hipocampo de víctimas de suicidio con historia de maltrato infantil, sin historia de maltrato y controles. Encontraron diferencias significativas entre los suicidas con historia de maltrato y el resto. Estos tenían menos niveles de ARN mensajero de los receptores glucocorticoides, así como una metilación (silenciamiento) mayor del promotor de la expresión de los mismos (NR3C1). Estos hallazgos relacionan una historia de maltrato en la infancia con una regulación epigenética de los receptores glucocorticoides que promueve una mayor y más sostenida respuesta de estrés ante eventos amenazantes.

Este tipo de investigaciones abre un campo nuevo para el estudio de la interacción entre procesos psicológicos y neurobiología. Ya no se trata solamente de conocer las modificaciones que determinadas influencias ambientales tienen en los circuitos neurales y hormonales, sino que se puede avanzar al estudio de la plasticidad del genoma en si mismo, a través de la regulación epigenética (McGowan et al., 2011). Así como los estudios sobre la base molecular de la memoria (Milner, Squire, \& Eric R Kandel, 1998) están permitiendo conocer la función de los cambios en la regulación de la expresión genética en el aprendizaje, los hallazgos sobre la regulación epigenética a través de los comportamientos de apego pueden abrir la puerta para comenzar a entender la interacción entre desarrollo, genética y psicopatología (Kendler \& Greenspan, 2006). Por ejemplo, actualmente se sabe que los efectos del cuidado maternal en ratas también afectan la expresión del gen GAD1, muy importante en la producción del neurotransmisor GABA y cuyas alteraciones en determinados circuitos neuronales están asociados a la esquizofrenia (Nakazawa et al., 2011). 


\section{DISCUSIÓN Y CONCLUSIONES}

En perspectiva, los modelos revisados dan cuenta de aspectos distintos y complementarios del apego. El apego como Sistema de Cuidado contribuye a explicar los mecanismos neurobiológicos que sostienen el comportamiento maternal de cuidado. Los componente regulatorios del apego permiten entender cómo esos comportamientos de cuidado ayudan a la cría a mantener su homeostasis interna (térmica, cardíaca, relación sueño/vigilia, hormonal, etc), principalmente, pero no únicamente, en las primeras etapas de aprendizaje. Ambos sistemas estarían biológicamente relacionados: así como el sistema nervioso del cuidador es acondicionado a través de la acción de ciertos neuropéptidos (oxcitocina, vasopresina, etc) y su interacción con los sistemas de neurotransmisión, el sistema nervioso de la cría posee características evolutivas que favorecen la eficacia de los comportamientos de cuidado (actividad y plasticidad del bulbo olfatorio, hiperactivación noradrenérgica del locus coeruleus, inmadurez de la amígdala y funcionamiento limitado del eje hipotálamohipófiso-adrenal). Por otra parte, las condiciones en que se produzca este comportamiento de apego podrían regular la expresión genética de las principales funciones emocionales (ej, respuesta al estrés) en las etapas vitales iniciales y su permanencia en la vida adulta del sujeto. Se trataría de un mecanismo para otorgar mayor plasticidad a las mismas de acuerdo a la interacción con las condiciones ambientales.

Un aspecto que no queda resuelto en los modelos explorados es cómo se integran estos hallazgos con sistemas anátomo-funcionales de mayor envergadura cuya función ha sido profusamente estudiada en las últimas décadas. Tal es el caso de la relación entre la amígdala y el condicionamiento del miedo, o en términos más generales, la respuesta a la amenaza.

En tal sentido existe evidencia sobre la existencia de un cerebro negativo, es decir, una serie de estructuras cerebrales que responden preferentemente a estímulos aversivos y/o amenazantes (Carretié, Albert, López-Martín, \& Tapia, 2009). Se trata de un mecanismo de respuesta rápido, automático, basado en lo perceptivo que permitiría una respuesta inmediata frente a un potencial peligro. Este sistema estaría conformado por un núcleo de estructuras cerebrales especializadas en la evaluación del potencial peligro de los estímulos. Dicho núcleo estaría compuesto por la amígdala, la corteza pre-frontal ventromedial y la ínsula. El producto de este sistema evaluativo generaría outputs a nivel conductual, potenciando respuestas motoras de afrontamiento y sensoriales, aumentando los niveles atencionales hacia los estímulos amenazadores. De la misma forma también existiría una modulación de los procesos cognitivos, en especial de la memoria de estímulos amenazadores, a través de las conexiones con el complejo hipocámpico (Dolcos, LaBar, \& Cabeza, 2005; LeDoux, 2000; Nader \& LeDoux, 1999; Phillips \& LeDoux, 1992).

Anteriormente se sostuvo que el apego en los primeros días de vida (en ratas) estaba relacionado con la resistencia a asociar el olor materno con sucesos aversivos, incluso choques eléctricos, y que dicha resistencia cumplía funciones adaptativas. Esta característica se relacionaría con cierta inmadurez de la amígdala en el período de aprendizaje inicial (hasta los 10 días). Pasada esta etapa, la amígdala asumiría un rol protagónico en el condicionamiento del miedo (Moriceau \& Sullivan, 2005). Por otra parte, hay estudios que muestran que el cambio comportamental ocurrido en la adolescencia está altamente correlacionado con cambios en el sistema nervioso. Estos cambios comportamentales modifican el balance entre inhibición/impulsividad frente a conductas de riesgo en favor del segundo término. El substrato neurobiológico de este fenómeno no se debe únicamente al empuje hormonal sino también a modificaciones estructurales en la corteza pre-frontal y en la amígdala, especialmente la mayor activación de las vías dopaminérgicas en dichas estructuras (Spear, 2000).

Por tanto, queda planteado en la investigación actual el problema de cómo influyen los comportamientos de apego en el desarrollo de la amígdala y en todo el sistema neuronal de respuesta a la amenaza. Por los estudios de Meaney y su grupo, se sabe que al menos la respuesta periférica a la amenaza es regulada epigenéticamente a través de los comportamientos de cuidado maternal (Zhang \& Meaney, 2010). Sin embargo, aún no se han identificado claramente los impactos hormonales, estructurales, de neurotransmisión y epigenéticos que tienen dichos comportamientos en el sistema córtico-límbico de respuesta a la amenaza.

Desde otro punto de vista son promisorios los estudios sobre el efecto en el desarrollo del sistema nervioso de las formas patológicas de 
apego, tanto en sus aspectos anátomo-funcionales (Moriceau, Raineki, J. D. Holman, J. G. Holman, \& Sullivan, 2009) como epigenéticos (McGowan et al, 2009). Los mismos permiten la estimación psicofisiológica del daño causado, la consecución de estrategias terapéuticas acordes y, en última instancia, la construcción de explicaciones más abarcativas de estos fenómenos.

Como se explicó en el apartado sobre la teoría del apego, este tipo de relación se mantiene en los humanos durante toda la vida y tiene una enorme influencia en el comportamiento sexual y social. Por lo tanto, surge la interrogante de cómo el apego no solo es capaz de regular la homeostasis fisiológica sino también como contribuye desde el punto de vista neurobiológico a la estructuración de funciones tales como la autorregulación emocional o las capacidades cognitivas más complejas. Es posible que para la consecución de estos fines no solo se requiera un avance en las técnicas de investigación neurocientífica sino también una creciente operacionalización de los conceptos de Bowlby y demás teóricos clásicos del desarrollo psicológico infantil. De esta manera, posibilitarán un abordaje empírico y neurobiológico de los mismos (Kandel, 1998; Kandel, 1999).

\section{REFERENCIAS}

Ainsworth, M.D. (1969). Object relations, dependency, and attachment: a theoretical review of the infant-mother relationship. Child Development, 40, 969-1025.

Alberch, P., Gould, S. J., Oster, G. F., \& Wake, D. B. (1979). Size and shape in ontogeny and phylogeny. Paleobiology, 5(3), 296-317.

Bale, T. L., Picetti, R., Contarino, A., Koob, G. F., Vale, W. W., \& Lee, K.-F. (2002). Mice deficient for both corticotropin-releasing factor receptor 1 (CRFR1) and CRFR2 have an impaired stress response and display sexually dichotomous anxiety-like behavior. The Journal of neuroscience: the official journal of the Society for Neuroscience, 22(1), 193-9.

Bale, T. L., \& Vale, W. W. (2004). CRF and CRF receptors: role in stress responsivity and other behaviors. Annual review of pharmacology and toxicology, 44, 525-57.

Bowlby, J. (1958). The nature of the child's tie to his mother. International Journal of Psycho-Analysis, 39, 350-373.

Bowlby, J. (1986). Vínculos afectivos: formación, desarrollo y pérdida. Madrid: Morata.

Bowlby, J. (1990). El vínculo afectivo (2a ed.). Buenos Aires: Paidós.
Champagne, D. L., Bagot, R. C., Hasselt, F. van, Ramakers, G., Meaney, M. J., Kloet, E. R. de, et al. (2008). Maternal care and hippocampal plasticity: evidence for experience-dependent structural plasticity, altered synaptic functioning, and differential responsiveness to glucocorticoids and stress. The Journal of neuroscience: the official journal of the Society for Neuroscience, 28(23), 6037-45.

Colin, V.L. (1991). Infant Attachment: what we know now. Informe del U.S. Department of Health and Human Services. Disponible en: PubMed.

Darwin, Ch. (1946). La expresión de las emociones. Buenos Aires: Intermundo.

Hofer, M. A. \& Sullivan R. M. (2001). Toward a Neurobiology of Attachment. En Nelson, Ch. A. y Luciana, M. (Eds). Handbook of Developmental Cognitive Neuroscience. Massachusetts: MIT Press.

Kendler, K., \& Greenspan, R. J. (2006). The Nature of Genetic Influences on Behavior : Lessons From "Simpler” Organisms. American Journal Of Psychiatry, 163, 1683-1694.

Ledoux, J. E. (2000). Emotions Circuits in the Brain. Annual Review of Neuroscience, 23, 155-184.

Lyons-Ruth, K., Melnick, Sh., Bronfman, E., Sherry, S. \& Llanas, L. (2004). Hostile- Helpless relational models and Disorganized Attachment patterns between parents and their young children: review of research and implications for clinical work. En Atkinson, L. y Goldberg, S. Attachment issues in Psychopathology and Intervention (p. 65-94). New Jersey: Lawrence Erlbaum Associates.

Liu, D., Diorio, J., Tannenbaum, B., Cladji, C., Francis, D., Freedman, A., et al. (1997). Maternal Care, Hippocampal Glucocorticoid Receptors, and Hypothalamic-Pituitary-Adrenal Responses to Stress. Science, 277(5332), 1659-1662.

Mcgowan, P. O., Sasaki, A., Alessio, A. C. D., Dymov, S., Szyf, M., Turecki, G., et al. (2009). Epigenetic regulation of the glucocorticoid receptor in human brain associates with childhood abuse. Nature neuroscience, 12(3), 342-348.

McGowan, P. O., Suderman, M., Sasaki, A., Huang, T. C. T., Hallett, M., Meaney, M. J., et al. (2011). Broad Epigenetic Signature of Maternal Care in the Brain of Adult Rats. (A. Sirigu, Ed.)PLoS ONE, 6(2), e14739.

Milner, B., Squire, L. R., \& Kandel, E. R. (1998). Cognitive Neuroscience and the Study of Memory. Review. Neuron, 20, 445-468.

Nakazawa, K., Zsiros, V., Jiang, Z., Nakao, K., Kolata, S., Zhang, S., et al. (2011). GABAergic interneuron origin of schizophrenia pathophysiology. Neuropharmacology. In press. doi: 10.1016/j.neuropharm.2011.01.022.

Nyberg, F., Linstrom, L. H. \& Terenius, L. (1988). Reduced $\beta$-casein levels in milk samples from patients with postpartum psychosis. Biol. Psychiat. 23, 115-122.

Panksepp, J., Moskal, J. R., Panksepp, J. B., \& Kroes, R. a. (2002). Comparative approaches in evolutionary psychology: molecular neuroscience meets the mind. Neuro endocrinology letters, 23 (4), 105-15. 
Panksepp, J. (1998). Affective Neuroscience. Oxford: Oxford University Press.

Panksepp, J. (2006). Emotional endophenotypes in evolutionary psychiatry. Progress in neuro-psychopharmacology \& biological psychiatry, 30 (5), 774-84.

Panksepp, J., \& Panksepp, J. B. (2000). The Seven Sins of Evolutionary Psychology. Evolution and Cognition, 6 (2), 108-131.

Piaget, J. (1991). Seis estudios de Psicología. Barcelona: Labor.

Pinel, J. (2007). Psicobiología. México: Pearson Education.

Rosenzweig, M.R. \& Leiman, A.I. (1992). Psicología Fisiológica. Madrid: McGraw-Hill Interamericana.
Spitz, R (1979). El primer año de vida del niño. Génesis de las primeras relaciones objetales. Madrid: Aguilar.

Weaver, I. C. G., Meaney, M. J., \& Szyf, M. (2006). Maternal care effects on the hippocampal transcriptome and anxiety-mediated behaviors in the offspring that are reversible in adulthood. Proceedings of the National Academy of Sciences of the United States of America, 103 (9), 3480-5.

Winnicott, D.W. (1960). The Theory of the Parent-Infant Relationship. Int. J. Psycho-Anal., 41, 585-595.

Zhang, T.-Y., \& Meaney, M. J. (2010). Epigenetics and the environmental regulation of the genome and its function. Annual Review of Psychology, 61, 439-66.

\footnotetext{
Para citar este artículo:

Barg Baltrame, G. (2011). Bases neurobiológicas del Apego. Revisión Temática. Ciencias Psicológicas V (1): 69-81.
} 